Original Article

\title{
Immediate effects of an end-range mobilization technique on shoulder range of motion and skin temperature in individuals with posterior shoulder tightness
}

\author{
Il-Young Yu, PT, BHSc ${ }^{1)}$, In-Gui Jung, PT, BHSc1), Min-Hyeok Kang, PT, PhD²), \\ Dong-Kyu Lee, PT, $\mathrm{PhD}^{2)}$, JAe-SeOP OH, PT, $\mathrm{PhD}^{3)^{*}}$ \\ 1) Department of Physical Therapy, Graduate School, Inje University, Republic of Korea \\ 2) Department of Rehabilitation Science, Graduate School, Inje University, Republic of Korea \\ 3) Department of Physical Therapy, College of Biomedical Science and Engineering, Inje University: \\ 607 Obang-dong, Gimhae-si, Gyeongsangnam-do 621-749, Republic of Korea
}

\begin{abstract}
Purpose] This study investigated the effects of an end-range mobilization technique on the range of motion of the glenohumeral internal rotation and the skin temperature of the shoulder in individuals with posterior shoulder tightness. [Subjects] Thirteen subjects with posterior shoulder tightness who had glenohumeral internal rotation deficit $\geq 15^{\circ}$ participated. [Methods] All subjects underwent glenohumeral joint end-range mobilization intervention. The internal rotation range of motion of the glenohumeral joint was measured by a goniometer and the shoulder skin temperature was measured by a digital infrared thermographic imaging device before and immediately after the intervention. Paired t-tests were used to analyze the differences in these parameter pre and post-intervention. [Results] The glenohumeral internal rotation range of motion and skin temperature of the posterolateral shoulder in increased significantly post-intervention. [Conclusion] The end-range mobilization technique is effective for increasing the glenohumeral internal rotation range of motion and skin temperature of the shoulder in individuals with posterior shoulder tightness.

Key words: End-range mobilization, Glenohumeral internal rotation deficit, Posterior shoulder tightness
\end{abstract}

(This article was submitted Jan. 9, 2015, and was accepted Feb. 14, 2015)

\section{INTRODUCTION}

Posterior shoulder tightness (PST) is a common cause of shoulder impingement syndrome, rotator cuff tear and labral lesions ${ }^{1,2)}$. PST is associated with glenohumeral internal rotation deficit (GIRD). Therefore, PST is often assessed by comparing the range of motion (ROM) of the glenohumeral internal rotation (IR) between the dominant and non-dominant sides ${ }^{3}$. Park et al. ${ }^{4}$ ) demonstrated decreased glenohumeral joint motion is correlated with decreased blood flow in subjects with impingement. Furthermore, Guirro et al. ${ }^{5)}$ demonstrated decreased talocrural joint motion is correlated with decreased blood flow and temperature in women with diabetes. Decreased joint motion leads to a biomechanical disadvantage, reducing the effectiveness of the pumping capacity of the muscle. Furthermore, PST changes the kinematics of the anterior and superior translations of the

*Corresponding author. Jae-Seop Oh (E-mail: ysrehab@inje. ac.kr)

(C2015 The Society of Physical Therapy Science. Published by IPEC Inc. This is an open-access article distributed under the terms of the Creative Commons Attribution Non-Commercial No Derivatives (by-ncnd) License $<$ http://creativecommons.org/licenses/by-nc-nd/3.0/> . humeral head, compromising the subacromial space and contributing to its impingement ${ }^{6)}$. Therefore, shoulder rehabilitation programs for PST should incorporate flexibility treatment to increase the glenohumeral IR ROM.

Various mobilization techniques for the PST treatment have been reported. Mobilization techniques that decrease PST increase the ROM of the glenohumeral joint and shoulder function ${ }^{7,9)}$. In addition, mobilization techniques including mechanical pressure stimulus increase blood flow $^{13)}$. Joint mobilization activates the sympathetic nervous system leading to increased blood flow and thus increased skin temperature ${ }^{12)}$. The high grade end-range mobilization technique was recently reported to be an effective treatment for PST ${ }^{11)}$, improving glenohumeral joint ROM and kinematics ${ }^{8,10)}$. Although this technique has been used clinically by physical therapists in Korea, no studies have investigated its effect on the shoulder of individuals with PST. Therefore, this study assessed the immediate effects of the end-range mobilization technique onj the glenohumeral IR ROM and skin temperature of the shoulder in individuals with PST.

\section{SUJECTS AND METHODS}

Thirteen men with PST (mean age, $29.15 \pm 2.85$ years; mean height, $177.12 \pm 3.88 \mathrm{~cm}$; mean weight, $77.93 \pm$ 
$10.32 \mathrm{~kg}$; mean GIRD, $\left.19.92 \pm 3.93^{\circ}\right)$ participated. The inclusion criteria were as follows: $(1) \geq 15^{\circ}$ of restricted movement in the glenohumeral IR ROM in the non-dominant side versus the dominant side; (2) had not performed sports activities during the past 6 months. Subjects with a history of surgery in the upper extremity, fracture, or neurological diseases were excluded. All subjects signed an informed consent form approved by the Institutional Research Review Committee of Inje University prior to participation.

The glenohumeral IR ROM was measured as described by Wilk et al..$^{2)}$; it was measured at $90^{\circ}$ shoulder abduction by two examiners using a goniometer. During IR ROM measurement, one examiner passively internally rotated the arm to the end of the range (with end feel, palpation of the coracoid process, and visualization of compensatory movement); this position was held as the goniometer was aligned and read by the second examiner.

The skin temperature of the shoulder was measured by using a digital infrared thermographic imaging (DITI) deviceThe DITI device (T-1000HD, MESH, Gangwon, Korea as described previously by Park et al. $\left.{ }^{4}\right)$. The temperature within the DITI room was kept between $19^{\circ} \mathrm{C}$ and $21^{\circ} \mathrm{C}$. The patients waited in the room for 15 minutes before measurement. DITI was performed on the upper body and the results were analyzed by evaluating the change in skin temperature of the shoulder at five points: anteromedial, anterolateral, posteromedial, posterolateral, lateral.

For the glenohumeral joint end-range mobilization technique, the subject's shoulder was positioned at the maximal IR at $90^{\circ}$ abduction, and grade IV posterior glide mobilization was performed. The 15 minute intervention comprised 30 second mobilizations followed by 30 second rests.

The differences in the glenohumeral IR ROM and skin temperature of the shoulder were analyzed by paired $t$-tests. Statistical analysis was performed using SPSS (version 18.0; SPSS, Inc., Chicago, IL, USA). The level of significance was set at $\mathrm{p}<0.05$.

\section{RESULTS}

The glenohumeral IR ROM increased significantly postintervention, as compared to pre-intervention $\left(55.69 \pm 8.11^{\circ}\right.$ vs. $\left.42.08 \pm 8.51^{\circ}, \mathrm{p}<0.001\right)$. Skin temperature increased significantly at the posterolateral point post-intervention $\left(35.43 \pm 1.20{ }^{\circ} \mathrm{C}\right.$ vs. $\left.34.88 \pm 1.19^{\circ} \mathrm{C}, \mathrm{p}=0.040\right)$. No significant differences were observed at the other points.

\section{DISCUSSION}

The results demonstrate the glenohumeral joint end-range mobilization technique significantly increased the glenohumeral IR ROM corroborating previous studies ${ }^{8,11)}$. Previous studies show that the end-range mobilization technique improves the flexibility of the glenohumeral joint capsule and stretches the soft tissue to induce an effect ${ }^{11)}$, Moreover, posterior gliding mobilization restores normal glenohumeral joint kinematics to ensure the humeral head glides in the appropriate direction ${ }^{7)}$.

If the IR ROM difference between the dominant and non-dominant sides exceed $\mathrm{m} 20^{\circ}$, which is classified as pathologic GIRD, there is an increased risk of shoulder disorder $^{2,3)}$. Pre-intervention, the IR ROMs the dominant and non-dominant sides were $42.08^{\circ}$ and $62^{\circ}$, respectively, for a difference of approximately $19^{\circ}$. After performing the endrange mobilization technique, the IR ROMs of the dominant and non-dominant were $55.69^{\circ}$ and $62^{\circ}$, respectively, for a difference of only approximately $6^{\circ}$. Therefore, the endrange mobilization technique, applied within the limit of the joint motion, restored the flexibility of the affected shoul$\mathrm{der}^{8,11)}$. Therefore, increasing the IR ROM and reducing the GIRD might decrease the risk factor of shoulder disorders.

The present study is the first to examine the effects of the end-range mobilization technique on skin temperature of PST. The results show skin temperature of the posterolateral area increased significantly post-intervention. This can be explained as follows: first, a vascular reaction, compresses the local tissue and causes reactive/ischemic hyperemia upon contact release; second, a neurologic sympathetic vascular reaction probably involving between blood pressure and heart rate variability adjustment may affect skin temperature regulation ${ }^{13)}$; third, a reddening reaction from sustained mechanical pressure leads to precapillary sphincter relaxation, resulting in increased blood flow and thus increased skin temperature ${ }^{14}$. Mobilization techniques such as mechanical pressure stimulus increase the blood flow and skin temperature of the local tissue, which relieve muscle spasms and soft tissue tightness.

The results of this study indicate that the end-range mobilization technique is effective for increasing the glenohumeral IR ROM and skin temperature of the shoulder in individuals with PST.

The present study has some limitations. In particular, we only compared the immediate effects of the end-range mobilization technique, including temperature. Therefore, future studies are needed to determine the long-term effects of this technique and its effects on temperature.

\section{ACKNOWLEDGEMENT}

This work was supported by the National Research Foundation of Korea Grant funded by the Korean Government (NRF-2014S1A5B8044097).

\section{REFERENCES}

1) Wilk KE, Reinold MM, Dugas JR, et al.: Current concepts in the recognition and treatment of superior labral (SLAP) lesions. J Orthop Sports Phys Ther, 2005, 35: 273-291. [Medline] [CrossRef]

2) Wilk KE, Macrina LC, Fleisig GS, et al.: Correlation of glenohumeral internal rotation deficit and total rotational motion to shoulder injuries in professional baseball pitchers. Am J Sports Med, 2011, 39: 329-335. [Medline] [CrossRef]

3) McClure P, Balaicuis J, Heiland D, et al.: A randomized controlled comparison of stretching procedures for posterior shoulder tightness. J Orthop Sports Phys Ther, 2007, 37: 108-114. [Medline] [CrossRef]

4) Park JY, Hyun JK, Seo JB: The effectiveness of digital infrared thermographic imaging in patients with shoulder impingement syndrome. $\mathrm{J}$ Shoulder Elbow Surg, 2007, 16: 548-554. [Medline] [CrossRef]

5) Guirro EC, Guirro RR, Dibai-Filho AV, et al.: Decrease in talocrural joint mobility is related to alteration of the arterial blood flow velocity in the lower limb in diabetic women. J Phys Ther Sci, 2014, 26: 553-556. [Medline] [CrossRef]

6) Huffman GR, Tibone JE, McGarry MH, et al.: Path of glenohumeral ar- 
ticulation throughout the rotational range of motion in a thrower's shoulder model. Am J Sports Med, 2006, 34: 1662-1669. [Medline] [CrossRef]

7) Manske RC, Meschke M, Porter A, et al.: A randomized controlled singleblinded comparison of stretching versus stretching and joint mobilization for posterior shoulder tightness measured by internal rotation motion loss. Sports Health, 2010, 2: 94-100. [Medline] [CrossRef]

8) Yang JL, Jan MH, Chang CW, et al.: Effectiveness of the end-range mobilization and scapular mobilization approach in a subgroup of subjects with frozen shoulder syndrome: a randomized control trial. Man Ther, 2012, 17 47-52. [Medline] [CrossRef]

9) Tyler TF, Nicholas SJ, Lee SJ, et al.: Correction of posterior shoulder tightness is associated with symptom resolution in patients with internal impingement. Am J Sports Med, 2010, 38: 114-119. [Medline] [CrossRef]

10) Park SW, Lee HS, Kim JH: The effectiveness of intensive mobilization techniques combined with capsular distension for adhesive capsulitis of the shoulder. J Phys Ther Sci, 2014, 26: 1767-1770. [Medline] [CrossRef]

11) Lin HT, Hsu AT, An KN, et al.: Reliability of stiffness measured in glenohumeral joint and its application to assess the effect of end-range mobilization in subjects with adhesive capsulitis. Man Ther, 2008, 13: 307-316. [Medline] [CrossRef]

12) Charkoudian N: Mechanisms and modifiers of reflex induced cutaneous vasodilation and vasoconstriction in humans. J Appl Physiol 1985, 2010, 109: 1221-1228. [Medline] [CrossRef]

13) Roy RA, Boucher JP, Comtois AS: Effects of a manually assisted mechanical force on cutaneous temperature. J Manipulative Physiol Ther, 2008, 31: 230-236. [Medline] [CrossRef]

14) William FG: Review of medical physiology, 22nd ed. New York: McGrawHill Companies, 2005. 